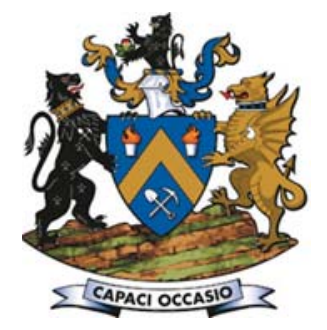

\title{
Potential use of thin spray-on liners for gas management in underground coal mines
}

\author{
by Z. Li*, S. Saydam*, R. Mitra*, and D. Chalmers*
}

\section{Synopsis}

Coal seam gas problems can adversely affect the safety and productivity of underground coal mines, leading to fatalities and financial losses.

Conventional gas management technologies using ventilation and gas drainage are unable to deal with the high and irregular gas emissions associated with high-production longwall mining. New technologies need to be developed to supplement the traditional gas management techniques to minimize the hazard of coal seam gas. Thin spray-on liners (TSLS) have gained some success for rock surface support since their introduction to the mining industry. Due to their relatively low permeability and appropriate mechanical properties, TSLs also show potential to be used as a gas management tool in underground coal mines.

In this paper we review the current gas management challenges and discuss the potential use of TSLs as a gas management tool in underground coal mines. This may involve reducing gas migration into the excavations/roadways, enhancing in-seam gas drainage, and preventing spontaneous combustion. Some potential areas for future research work are identified.

Keywords

thin spray-on liner (TSL), gas management, underground coal mining.

\section{Introduction}

When a coal seam is influenced by mining activities, gas stored inside is liberated into the underground ventilation system. Gas emissions have created serious difficulties for the coal mining industry around the world. Therefore, coal mines have to develop effective strategies to control the gas concentration below the threshold value to meet statutory requirements. Ventilation has been the first solution in gas management for underground coal mining. When the emitted gas cannot be effectively diluted by ventilated air, gas drainage using pre- and/or post-drainage has to be introduced. However, even with ventilation and gas drainage, irregular gas emissions usually increase the gas concentration in roadways and slow down the development rate, thus causing significant economic loss to the coal mining industry (Thakur, 2006). Therefore, new technologies need to be developed to address this issue and mitigate the explosion risk.

A thin spray-on liner (TSL) is a thin chemical-based coating or layer that is applied onto mining excavations with a thickness of 3 to $5 \mathrm{~mm}$ (Lau et al., 2008; Richardson et al., 2009; Saydam and Docrat, 2007). Due to the operational benefits regarding both safety and logistics, TSLs have achieved some success as a ground support tool for some specialized applications, such as repairing shotcrete (Lacerda and Rispin, 2002), supporting the hangingwall in gold mines (Carstens and Oosthuizen, 2004) and supporting the longwall T-junction sections in coal mines (Thyrock et al., 2010).

Besides ground support, due to their relatively low permeability TSLs also show potential to be used as a gas management tool in underground coal mines. For gas emission control purpose, TSLs may serve as a sealing skin to prevent irregular gas emissions from the ribs and keep the gas concentration in the roadway below the statutory requirements and guarantee the development rate. For gas drainage enhancement purpose, TSLs can prevent the ventilation air from migrating into the gas drainage boreholes and increase the gas drainage efficiency. For spontaneous combustion control, TSLs have the potential to slow down the oxidation process or even stop it due to the lack of oxygen migration through the coal seam.

\section{Overview of thin spray-on liners \\ Background}

TSLs are multicomponent polymer materials that can be applied to a rock mass surface at a thickness of 3-5 mm as a sealant or as surface support (Saydam and Docrat, 2007). There are many TSL products on the market. They differ by mix type such as liquid/liquid or liquid/powder and by polymer-based type (Northcroft, 2006). The polymer-based TSLs

* School of Mining Engineering, UNSW Australia, Sydney, Australia.

(C) The Southern African Institute of Mining and Metallurgy, 2016. ISSN 2225-6253. Paper received Nov. 2014; revised paper received Nov. 2015. 


\section{Potential use of thin spray-on liners for gas management}

can be classified into six groups: acrylics, liquid latex where latex is any known polymer, polyurethane, polyurea, methacrylate, and hybrid (Kaiser and Suorineni, 2006).

Depending on the curing mechanism and liner formation, TSLs are categorized into two different types: reactive and nonreactive (Rispin and Garshol, 2003). Reactive TSLs cure quickly, but are sensitive to water and barely stick to wet surfaces; furthermore, they can only be applied with strict safety precautions. On the other hand, nonreactive TSLs cure slower but bond well to wet and dry surfaces and can be applied with normal safety precautions (Kaiser and Suorineni, 2006; Northcroft, 2006). For safety reasons, the majority of current products on the market are nonreactive, with modifications to reduce the curing time.

TSLs are more flexible than shotcrete, which has a typical thickness of 25-100 mm depending on the need. Effective polymer support is created by a continuous membrane, which adheres firmly to the rock. An 'ideal' TSL should have appropriate mechanical properties and comply with a number of operational, environmental, and economic standards. A list of desirable characteristics of an ideal TSL is shown in Table I. The manufacture of a number of TSL products has been stopped, since they do not possess adequate physical or chemical properties. However, newer products are continuously developed and introduced (Yilmaz, 2007).

\section{Use of thin spray-on liners}

TSLs had been used in civil engineering as sealants for many years before being introduced to the mining industry (Kuijpers, 2004; Yilmaz et al., 2003). TSL materials for the mining industry were initially designed as sealants to limit the weathering of rock, and later were intended to be used as a substitute for mesh or shotcrete (Spearing et al., 2009; Yilmaz, 2007). The idea of using TSLs as surface support was initiated in the late 1980s in Canada and was originated by the thought that a liner as thin as $5 \mathrm{~mm}$ should perform the same as, or even better than, shotcrete (Archibald, 2004; Yilmaz, 2011). Since the 1990s, TSL support has become a focus of mining industry due to the considerable operational benefits, with the potential to reduce mining costs (Ozturk, 2012).

\begin{tabular}{|c|c|}
\hline Property or characteristic & Recommended range \\
\hline Non-combustible & Flame spread ratingmax $<200$ \\
\hline Tensile strength & $>5 \mathrm{MPa}$ \\
\hline Adhesion strength & $\begin{array}{c}>1 \mathrm{MPa} \text { (hard rock) } \\
>3-4 \mathrm{MPa} \text { (weatherable ground) }\end{array}$ \\
\hline Shear strength & $>2 \mathrm{MPa}$ \\
\hline Curing time & $<1 \mathrm{~h}$ \\
\hline Temperature tolerant & $0-50^{\circ} \mathrm{C}$ \\
\hline Application rate & $>1 \mathrm{~m}^{2} / \mathrm{min}$ \\
\hline Pot life & $>1 \mathrm{~h}$ \\
\hline Cost & $<\$ 20$ per $\mathrm{m}^{2}$ \\
\hline Application & Minimal or no surface preparation \\
\hline Rebound & $<5 \%$ \\
\hline
\end{tabular}

TSLs have undergone research and development for over 20 years, with numerous trials conducted in underground mines. Belfield (2006) reported that over 50 mines around the world have used TSLs for rock support. Potvin et al. (2004) listed the most common usages of TSLs, and these applications were usually at locations with exceptionally unfavourable ground conditions or ground control problems (Yilmaz, 2011).

> Support between rock anchors

> Supporting areas with limited access and/or logistics constrains

> Mesh replacement

> As primary support immediately after blasting

> Temporary support (can be covered by shotcrete at later stage if necessary)

> Temporary support in TBM tunnels (permanent support can be installed behind the equipment)

> Reducing rockburst damage

> Pillar reinforcement

$>$ Face support

- Large machine borehole lining and stabilization

> Stabilization of return air tunnel

> Orepass lining

> Prevention of rockfalls caused by unravelling, slabbing, or loosening of small blocks of rocks

- Rigid ventilation seals

> Prevent ground degradation from weathering fretting and swelling.

In spite of the adverse ground conditions, most of the TSL trials have proved to be successful for their planned application in specific areas (Potvin et al., 2004). For some TSL application cases, poor bonding, falling of large slabs, peeling, tearing, and damage due to blasting and moving machinery were observed (Nagel and Joughin, 2002; Tannant, 2001). In these applications, TSLs were used mainly for temporary support for strata control and ground stabilization. However, the use of TSLs is still limited to special applications rather than to general application as a systematic surface support, as are mesh and shotcrete. Their use has not become widespread in underground mines.

The advantages of TSLs are fast application rates, rapid curing time, reduced material handling compared to shotcrete, high tensile strength with high areal coverage, high adhesion which enables early reaction against ground movement, and ability to penetrate into joints (Kuijpers et al., 2004; Pappas et al., 2003). These properties ease logistics, improve on cycle times, increase mechanization, and improve safety for underground support (Stacey, 2001). In spite of these benefits, the original aim of using TSLs as an alternative to mesh and shotcrete has not yet been achieved. Most of the products on the market are still undergoing study and field trials, and no reports yet exist about TSLs being systematically applied as surface support in mines (Darling, 2011). Several reasons may contribute to this. Firstly, the support that a TSL can provide is not fully understood (Tannant, 2001) although many efforts have been made to study the support mechanism using analytical (Fowkes et al., 2008; Mason and Abelman, 2009; Mason and Stacey, 2008) and numerical (Dirige and Archibald, 2009; Tannant and Wang, 2002; Wang and Tannant, 2004) methods. Secondly, the design of TSLs as surface support systems is currently based 


\section{Potential use of thin spray-on liners for gas management}

on experience, assumptions and field observations, and cost considerations (Jjuuko and Kalumba, 2014), and application guidelines are needed for using TSLs as a surface support for different ground conditions. Thirdly, there is still a lack of standard laboratory test methods to determine the mechanical properties of TSLs, with only tensile and tensile-bond strength tests having met with general acceptance from TSL stakeholders to date (Archibald, 2001); this makes it very difficult to compare and select among different TSL products.

TSL technology is not yet mature and still under development. It should be noted that a TSL application may not replace traditional ground support such as rockbolts. However, TSLs have performed well when combined with other types of support, such as rockbolts plus TSL plus shotcrete and rockbolts plus TSL plus mesh plus shotcrete (Hussain et al., 2012).

\section{Permeability characteristics of thin spray-on liners}

Besides ground support, a report by European experts also mentioned the advantage of using TSLs as a barrier against gas movement because of their relatively low permeability (EFNARC, 2008). During the past few years, much research has been carried out to study the permeability characteristics of different TSLs.

The first permeability test of a TSL reported in the literature was by Archibald and de Souza (1993), who investigated the potential of a polyurethane-based TSL for blocking radon gas entry. They carried out radon gas permeability tests with different TSL thicknesses. Their results showed that with a thickness of $0.37 \mathrm{~mm}$, the TSL product tested could effectively reduce the radon flux by as much as $94 \%$, and such potential promised to improve significantly with increasing TSL thickness. Archibald and de Souza (1993) emphasized the potential use of TSLs in restricting hazardous gas inflows. It is important to note that the hazardous gases, easily diffusing from rock pores into the working area, cannot be effectively blocked by shotcrete due to its high permeability (Tannant, 2001).

Similar tests were conducted by Saghafi and Roberts (2001). They measured the permeability of a cement latexbased TSL product for methane, carbon dioxide, and carbon monoxide. Their results indicate that the permeability of the tested TSL is in the range of nanodarcies. They reported that the permeabilities for methane and carbon dioxide are very similar, whereas the permeability for carbon monoxide is a few times higher. However, both the tests conducted by Archibald anddDe Souza (1993) and Saghafi and Roberts (2001) considered only the TSL material itself, without considering the substrate it was applied to; the substrate will determine the adhesion strength for a particular TSL material. Previous test results show that there is a linear relationship between the efficiency of the TSLs in controlling gas flow and their adhesion strength to the substrate (Hussain et al., 2012).

Considering the interaction between TSLs and the substrate applied, Mass and Renken (1997) conducted radon gas permeability tests on concrete coated by different cementitious-based TSLs with the test apparatus shown in Figure 1. Their results showed that the coatings tested all exhibited excellent permeability coefficients; two to three orders of magnitude smaller than the average concrete permeability coefficient. Mass and Renken (1997) further stated that any sealants placed on a highly permeable concrete would greatly reduce the permeability.

In order to investigate the potential of TSLs as a gas management tool in underground coal mines, Hussain et al. (2012) carried out permeability tests on coal samples coated with three different TSL materials (two polymer/ cementitious-based TSLs and one cement/latex TSL) of varying thicknesses. The tested gases include carbon dioxide and nitrogen. A 'Hassler' type core holder was used for this test, as shown in Figure 2. The experimental results indicate that the TSLs tested could reduce the gas permeability of coal by up to three orders of magnitude. This was the first test to investigate the potential use of TSLs for coal mine gas management, and the results showed favourable potential. However, the permeability tests were conducted only with nitrogen and carbon dioxide; methane, the gas of main concern in underground coal mining, was not tested. The influence of gas adsorption on permeability was not considered in the test either, which influenced the accuracy of the results, as coal permeability is pressure-dependent due to different degrees of gas adsorption (Zhou et al., 2013a, 2013b).

Permeability results from TSLs of different mix base chemistries were compared based on the literature available, and the following order of permeability obtained: polymer/cementitious-based TSL < polyurethane-based TSL < cementitious-based TSL. Specifically, the permeability of polyurethane-based TSL is about one order of magnitude lower than that of the cementitious-based TSL; while the permeability of polymer/cementitious-based TSL is about four to five times lower than that of cementitious-based TSL. The polymer modifications can significantly reduce the permeability of TSLs, and this finding also conforms with previous research results (Golsby, 2015).

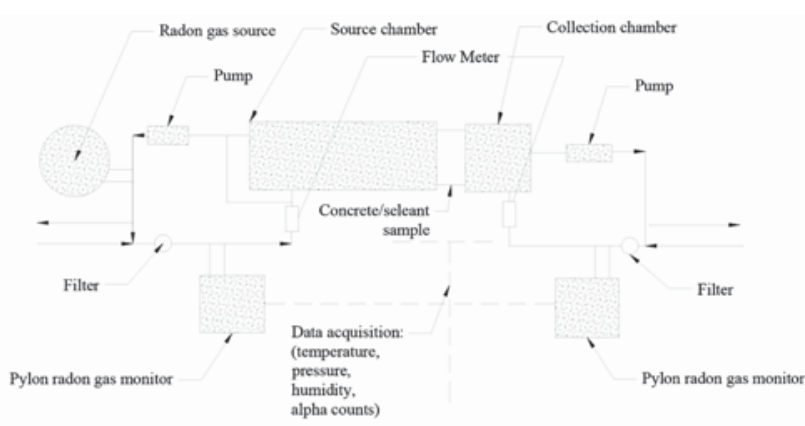

Figure 1-Schematic of permeability test apparatus for concrete and TSLs (Mass and Renken, 1997)

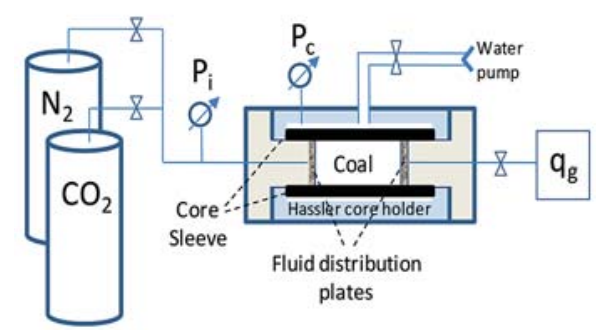

Figure 2-Schematic of experimental apparatus for permeability test (Hussain et al., 2012) 


\section{Potential use of thin spray-on liners for gas management}

\section{Gas emission and control in underground coal mines \\ Gas emission into mine workings}

The quantities of gas contained in coal seams are a function of the degree of coalification and permeability of the overburden (Noack, 1998). When influenced by mining excavations, the gas is emitted into the ventilation system. Inadequate air quantities in the ventilation system may cause gas to accumulate to dangerous levels, and may result in gas explosions under certain circumstances and conditions (Lunarzewski, 1998). Table II shows some of the major mine explosions since 2000 (Karacan et al., 2011; State Administration of Coal Mine Safety, 2014; United Nations, 2010). Due to the explosion risk, gases have always been regarded as a threat in underground coal mining. Every coal mine has to institute effective gas control strategies to maintain the gas concentration in the working areas below the statutory requirements.

The amount of gas emitted into mine workings depends on a number of factors. The most important of these are the productivity of the coal mine, the gas content of the coal seam, presence of other coal seams in the vicinity of the seam being worked, operational variables, and geological conditions (Karacan et al., 2011).

Gas emissions in underground coal mines can be classified into emissions from development ribs and from longwall panels. Although many methods have been developed for estimating gas emission for both development and longwall panel production stages (Karacan et al., 2011; Lunarzewski, 1998; Noack, 1998), these methods often lack accuracy due the numerous defining parameters and assumptions involved. Besides, irregular gas emission makes the estimation more difficult.

\section{Gas emission in development excavations}

As headings advance into the virgin coal seam, free and adsorbed gas from the immediate ribs of a development heading are released. Typically, the rib emission rate is a function of the age of the rib. Initially, the emission rate is relatively high, followed by a rapid decay from this peak to a residual level. This process can be described by Equation [1] and Figure 3 (Moreby, 2005):

$$
E_{g}=E_{0} \cdot e^{-\lambda t}+E_{r}
$$

where, $E_{g}$ is the rib emission rate in $\mathrm{L} / \mathrm{s} / 100 \mathrm{~m} ; E_{0}$ is the initial gas emission rate $(t=0)$ in $\mathrm{L} / \mathrm{S} / 100 \mathrm{~m} ; \lambda$ is the rate of decay; and $E_{r}$ is the residual emission $(t=\infty)$ in L/s/100 m.

For development headings, the total amount of gas liberated from coal at the face over a period is dependent upon the gas content of the coal and the mining rate. However, gas emission at the face is not regular but fluctuates over very wide limits, depending upon the mean mining rate and method of mining (Vutukuri and Lama, 1986). Strategies must be adopted to control this irregular gas emission to establish workable conditions in the development headings.

\section{Gas emission at longwall faces}

In longwall mining, gas is emitted from the seam being mined as well as from the surrounding medium, which may contain very large amounts of gas, particularly in the surrounding seams. Saghafi et al. (1998) demonstrated that the amount of mine gas emissions exceeded the gas content of coal by a

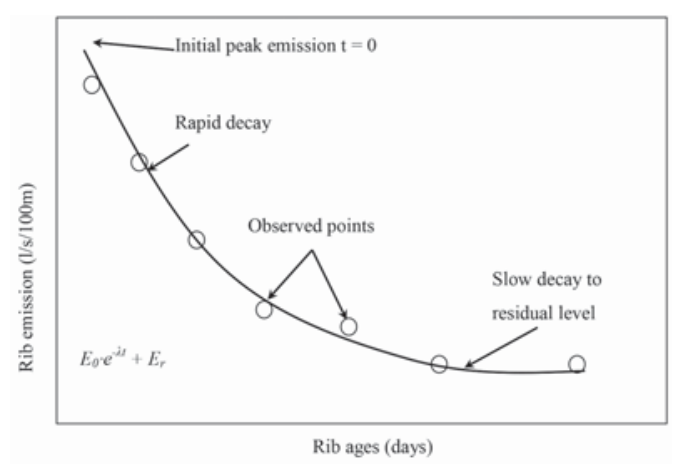

Figure 3-Characteristics of gas emission decay (modified from Moreby, 2005)

Table II

Major coal mine explosion incidents since 2000 (modified from Karacan et al., 2011; State Administration of Coal Mine Safety, 2014; United Nations, 2010)

\begin{tabular}{|c|c|c|c|}
\hline Country & Date & Coal mine & Fatalities \\
\hline China & 14 February 2005 & Sunjlawan, Haizhou shaft, Fuxin & 214 \\
\hline USA & 2 June 2006 & Sago, West Virginia & 12 \\
\hline Kazakhstan & 20 September 2006 & Lenina, Karaganda & 43 \\
\hline Russia & 19 March 2007 & Ulyanovskaya, Kemerovo & 108 \\
\hline Ukraine & 19 November 2007 & Zasyadko, Donetzk & 80 \\
\hline USA & 5 April 2010 & Upper Big Branch, West Virginia & 29 \\
\hline Turkey & 17 May 2010 & Karadon, Zonguldak & 30 \\
\hline New Zealand & 19 November 2010 & Pike River Mine & 29 \\
\hline China & $\begin{array}{c}29 \text { March } 2013 \\
1 \text { April } 2013\end{array}$ & Babao, Baishan, Jilin & $\begin{array}{l}36 \\
17\end{array}$ \\
\hline China & 12 May 2013 & Taozigou, Luxian, Sichuan & 28 \\
\hline China & 13 December 2013, & Baiyanggou, Hutubi, Xinjiang & 21 \\
\hline China & 21 April 2014 & Hongtutian, Yunnan & 14 \\
\hline
\end{tabular}




\section{Potential use of thin spray-on liners for gas management}

factor of four, due to the emissions from the overlying and underlying strata, as shown in Figure 4. Therefore, gas emissions during longwall mining are very difficult to predict and may depend on many factors besides the gas content of the mined coal.

\section{Control of gas emissions}

As the coal mining environment becomes deeper and gassier, problems associated with gas management becomes more significant (Karacan et al., 2011). A well-designed ventilation system can deal with low to medium gas emission problems. When it is not economic or not operationally practicable to manage gas emission by ventilation alone, gas drainage using pre-drainage and/or post-drainage is required to reduce the gas emissions in the working areas.

\section{Diluting gas with ventilation}

Ventilation has been the first recourse for controlling gas emissions (Karacan, 2008; Karacan et al., 2007; Noack, 1998). The supply of sufficient fresh air to dilute the gas to safe limits and render it relatively harmless is essential for the safety of longwall mining (Schatzel et al., 2008). This method is applicable only in mines where gas emission is low to medium. The system will fail when high gas emission is encountered because of high costs and unacceptable air velocities at the working places. Thakur (2006) indicated that with a well-designed ventilation system, it is economically feasible to handle specific gas emissions up to $28.3 \mathrm{~m}^{3}$ per ton of coal mined.

\section{Gas drainage}

Mine operators often try to supply maximum ventilation air based on the capacity of the system to dilute the gas concentration. Nevertheless, as time passes and the roadways become longer, ventilation capacity may decline because of leakage (Schatzel et al., 2008). Furthermore, gas emissions that flow into the ventilation system may increase as mines progress into deeper and gassier coal seams, and as longwall operation parameters change (e.g. increased advance rates) (Karacan et al., 2011). Consequently, it has become increasingly difficult to control the gas concentration below statutory requirements by ventilation alone, as this will require impractically large quantities of air (Gillies and $\mathrm{Wu}$, 2013).

When it is impractical to control gas concentration by ventilation alone, gas drainage using pre-drainage and/or post-drainage techniques has to be introduced to reduce the gas contents and emissions (Brunner et al., 1997).

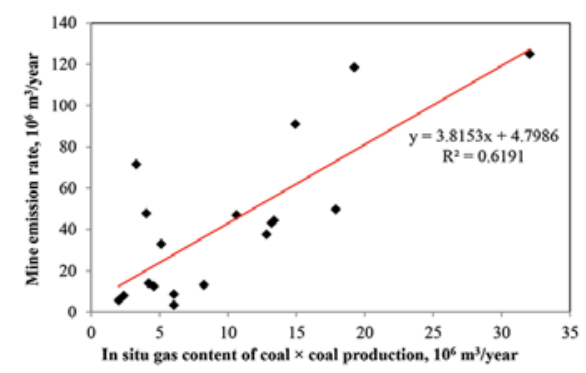

Figure 4-Mine emissions versus gas content of mined coal (modified from Saghafi et al., 1998)
Pre-drainage methods aim to reduce the gas content of the coal seam before mining for the purpose of reducing gas emissions during development and longwall production. Post-drainage methods (also known as goaf or gob drainage) aim to capture gas during longwall phases to reduce the amount of gas managed by ventilation.

When coal seams have a sufficiently high natural permeability, gas drainage has been a positive and reliable method for controlling high gas emissions in mines. DuBois et al. (2006) investigated the use of in-seam boreholes for shielding the entries from gas flow. Their results showed that after gas drainage for 6 to 24 months prior to any mining, the gas emissions into the entries reduced by between $30 \%$ and $35 \%$. However, gas drainage has met with limited success in low-permeability coal. Almost $50 \%$ of the underground inseam gas drainage programmes delivered little to no benefits to gas content reduction (Black and Aziz, 2008). Besides low permeability, many other factors also restrict the efficiency of in-seam gas drainage (Black and Aziz, 2009):

$>$ Insufficient drainage time prior to intersection by development gateroads

> Insufficient monitoring and management of borehole performance, resulting in low to no flow due to accumulation of water and/or coal fines within the borehole

> Insufficient monitoring and management of the gas reticulation pipe network, with blockages or significantly restricted flow capacity due to accumulation of water and/or fines in sections of the range

> Poor standard of sealing holes following intersection by development, resulting in air in the pipe range and reduced suction pressure

> Insufficient standpipe length and sealing (grouting) standard, resulting in air dilution in the pipe range and reduced suction pressure

> Boreholes drilled down-dip and not in the optimum orientation for maximum drainage performance

> Absence of in-hole dewatering where boreholes have been drilled down-dip, resulting in water accumulation restricting gas desorption.

A method that can offer a substantial increase in drainage time is surface-to-inseam drilling (Black and Aziz, 2009). This method allows drainage to take place for several years prior to mining (Thakur, 2006). However, with very low permeability strata this method has limited success in reducing the gas content (Packham et al., 2011).

A promising technique referred to as 'enhanced gas recovery' was firstly described by Puri and Yee (1990). This technique involves injecting a gas, which is different to the seam gas, into the coal seam to stimulate methane (or other gas) production (Packham et al., 2011). This technique may help to increase the production of gas from coal seams and improve the recovery rate from low-permeability coal. Although promising, this technique is still under development, and the mechanism for the stimulation is not yet fully understood.

As the seams worked become deeper and gassier, gas drainage has been progressively adopted to reduce the in situ gas content and gas emission. However, gas drainage is effective only for coal seams with high permeability; besides, gas drainage needs time to become effective and it cannot 


\section{Potential use of thin spray-on liners for gas management}

solve the irregular gas emission problem in underground coal mines timeously, which may cause the stoppage of work in development headings and longwall faces.

The limitations of both ventilation and gas drainage require new techniques to be developed to deal with irregular gas emission problems, enabling development and production activities to continue uninterrupted.

\section{Potential uses of TSLs for gas management}

\section{Gas emission control with TSLS}

During longwall development, headings are driven into gassy coal and gas is released as the seam is depressurized, at a rate that is a function of gas content, pressure, and permeability (Noack, 1998). When ventilation and gas drainage are not sufficient to control the gas emissions, the development headings have to be stopped for safety reasons, which is not acceptable for mining companies. A technology is urgently needed for reducing the gas emissions rate in this situation, allowing the headings to advance.

Due to their relatively low permeability, TSLs may have the potential to deal with irregular gas emissions. Their operational benefits, such as rapid application, rapid curing, and low volume required allow the timely sealing of the irregular gas emission area. Their appropriate mechanical properties, such as high tensile strength and elongation, can also deal with deformable ground conditions. It is worth pointing out that these benefits cannot be provided by other sealing techniques such as shotcrete. A schematic of TSL applied in an irregular gas emission area is shown in Figure 5. The application of TSL may reduce the gas emission rate in the development heading and allow the advance of the heading. Besides the gas management benefits, application of a TSL may also help to maintain the stability of the fresh excavations.

Based on the permeability test results of Saghafi and Roberts (2001), Gerard (2007) conducted a theoretical analysis of the effectiveness of TSLs in reducing rib emissions. He stated that a sharp drop in rib emissions would occur once TSL spraying begins, and this process is illustrated in Figure 6. Although the study showed the potential for reducing rib emissions with TSLs, there was no field trial or data to support these assumptions. However, these theoretical results did show the potential of TSLs for reducing rib emissions and field trials are recommended to prove these assumptions. At the same time, problems associated with the application of TSLs can be addressed.

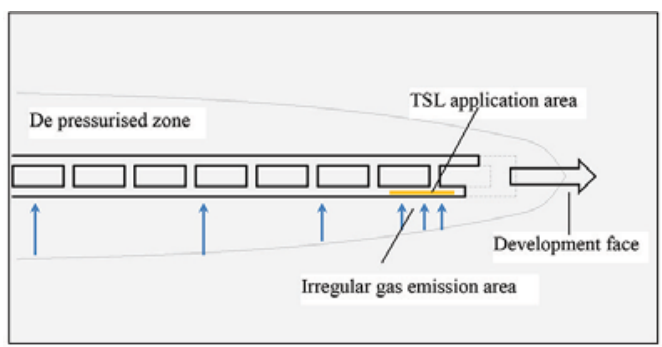

Figure 5-Areal TSL support for gas emission control during longwall development

\section{Enhancing in-seam pre-drainage with TSLs}

Because of the influence of the excavation, stress-induced rock fracture near the roadway will increase the permeability of the coal mass near the roadway (Zhou and Lin, 1998), as shown in Figure 7. This will cause serious air leakage around a drainage borehole due to the high suction pressure created by gas drainage (Xia et al., 2014a), as shown in Figure 8a. This air leakage may not only result in a low gas drainage concentration, but also lead to many other hazards, such as spontaneous combustion of coal, gas combustion, and gas explosion (Xia et al., 2014b). Apart from the risks, Palchik (2002) stated that if the migration air can be reduced by onehalf to one-third, the drained gas flow rate can increase 1.5-2 times. Therefore, there is an urgent need to develop an effective method to deal with ventilation air migration into the drainage boreholes.

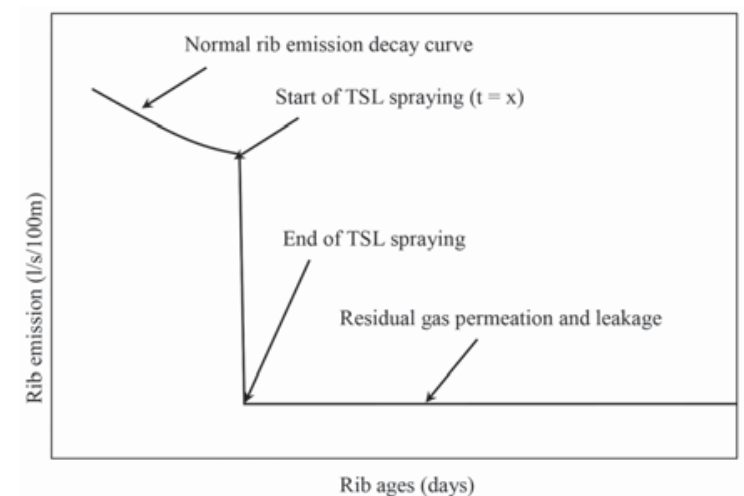

Figure 6-Theoretical rib emission curve with TSL applied at $t=x$ (modified from Gerard, 2007)

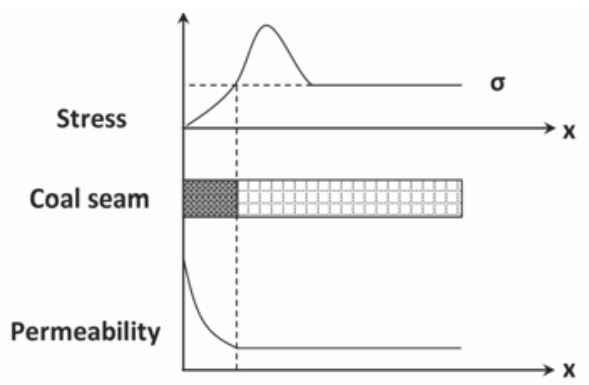

Figure 7-Change in coal seam permeability due to excavations (modified from Zhou and Lin, 1998)
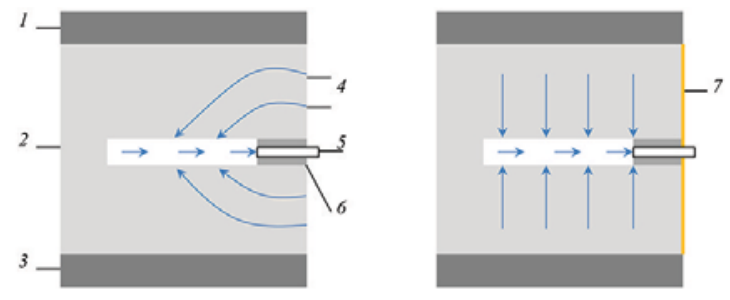

(a) Ventilation air migrates into drainage borcholes (b) TSL reduce ventilation air migration

1 - Roadway roof, 2 - coal seam, 3 - roadway floor, 4 - ventilation air migrates into drainage borehole, 5 - drainage borehole, 6 - drainage borehole seal, 7 - TSL material

Figure 8-Use of TSLs in reducing air migration into drainage boreholes 


\section{Potential use of thin spray-on liners for gas management}

Measures need to be taken to deal with this air leakage around gas drainage boreholes. In gas drainage practice, a sealing material such as polyurethane is used to seal the borehole; however, it can seal only the borehole itself, and the internal cracks of the coal seam are not blocked off (Lu et al., 2014). A TSL may be used to reduce the migration of ventilation air into the drainage boreholes. After spraying, the TSL material will bond firmly to the coal ribs and form a liner with low permeability. The liner can seal the cracks around the drainage holes and prevent the migration of ventilation air into the drainage holes, as shown in Figure 8b. The performance of the drainage hole is enhanced: on the one hand, the purity of the drained gas is increased as the path between the ventilation air and the drainage holes is sealed; on the other hand, the suction pressure can help desorption of gas from the coal and increase the gas production. Furthermore, the TSL can also reduce the rib emission rate to the ventilation system, which enhances gas management in underground coal mines.

A field trial of using TSL for enhancing the gas drainage efficiency was carried out by Tenney et al. (2015). The trial involved spraying a polymer/cementitious-based TSL on the area surrounding gas drainage boreholes, whereby the TSL acts as a thin membrane decreasing the permeability of the coal. The results showed that the methane purity was increased by $9.14 \%$ and air contamination reduced by $7.93 \%$ after the application of the TSL. However, problems are also associated with the trials, such as the variability of the methane flow rate, the interpretation of the results, and the area for spraying the TSL material, which need to be investigated in future tests. The advantages and disadvantages of gas emission control techniques are compared in Table III.

\section{Spontaneous combustion control with TSLs}

Spontaneous combustion of coal has been a serious problem for coal producers and users for many years. As a result of spontaneous combustion, the coal producers may suffer (Ham, 2005; Simion et al., 2005):

- Fatalities caused by hazardous gases

> Loss of equipment

> Loss of a large amount of coal reserves.
It is important for the mine ventilation engineer to be conscious of the zones in which spontaneous combustion is most likely to occur. Typical areas where spontaneous combustion can occur are along ventilation leakage paths. Leakage can occur in rib fractures around ventilation stoppings, through faults or cracks passing through a pillar, or along the bed separation in any remaining coal left in the roof (Ham, 2005; McPherson, 1993). Oxygen may accumulate in these areas where insufficient ventilation exists, resulting in the inadequate dispersion of heat from oxidation (Cliff, 2009).

TSLs have the potential for controlling spontaneous combustion. If a spontaneous combustion event was discovered in a chain pillar, then a TSL could be sprayed on the ventilation intake side to prevent any further oxygen from entering the leakage path. If detected early enough, the oxidation process may slow down and eventually be stopped due to the oxygen deficiency. In fact, if a TSL has already been sprayed onto the ribs (whether for support or other gas management reasons), spontaneous combustion may have been avoided already, as shown in Figure 9.

\section{Ventilation benefits provided by TSLs}

Ventilation power costs have a direct relationship with frictional head losses in mine airways. A reduction in the airway friction factor would result in a corresponding reduction in power costs. TSLs have a very low ventilation

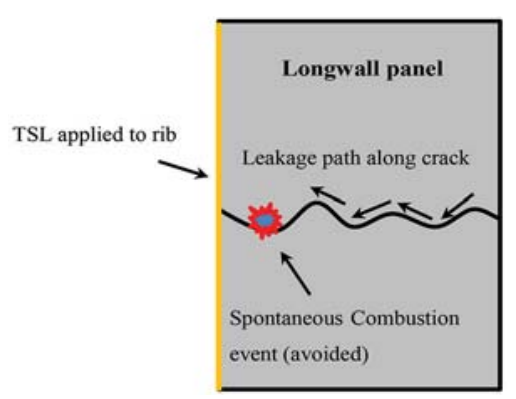

Figure 9-Example of TSL possibly preventing spontaneous combustion

\section{Table III}

\section{Advantages and disadvantages of different gas emission control techniques}

\begin{tabular}{|c|c|c|}
\hline Technique & Advantages & Disadvantages \\
\hline Ventilation & $\begin{array}{l}\text { - Most common method of dealing with gas emission } \\
\text { - Applicable in mines with low to medium gas emission }\end{array}$ & $\begin{array}{l}\text { - Not effective with high gas emission, because of high costs } \\
\text { and unacceptable air velocities } \\
\text { - Ventilation capacity may decline due to leakage }\end{array}$ \\
\hline Gas drainage & $\begin{array}{l}\text { - Reliable method for controlling high gas emission in mines } \\
\text { - Reduces the gas content of the coal seam and } \\
\text { shields the development entry } \\
\text { - Can capture gas for power generation }\end{array}$ & $\begin{array}{l}\text { - Needs long drainage time prior to intersection by development road } \\
\text { - Limited success in low-permeability coal } \\
\text { - Fractures around the drainage pipe, resulting in air dilution and } \\
\text { reduced suction pressure } \\
\text { - Cannot deal with irregular gas emissions }\end{array}$ \\
\hline TSL & $\begin{array}{l}\text { - Very low permeability } \\
\text { - Can deal with irregular gas emissions } \\
\text { - Many operational benefits such as rapid application, } \\
\text { rapid curing, low volume required } \\
\text { - Can bring other benefits such as ground support, } \\
\text { spontaneous combustion control, and reducing the } \\
\text { ventilation friction factor }\end{array}$ & $\begin{array}{l}\text { - TSL cannot be applied alone to control gas emission; it has to be } \\
\text { applied to supplement other techniques }\end{array}$ \\
\hline
\end{tabular}




\section{Potential use of thin spray-on liners for gas management}

friction factor, which gives them potential to improve mine ventilation capabilities (Archibald and de Souza, 1993; de Souza and Archibald, 2002).

Archibald and de Souza (1993) carried out wind tunnel simulations of airways, made of plywood, to evaluate the friction factor $(K)$ parameters associated with the installation of a polyurethane-based TSL. This work demonstrated that the TSL used had a ventilation friction factor about $0.00249 \mathrm{~N} . \mathrm{s}^{2} / \mathrm{m}^{4}$, which is approximately two to four times lower than that of typical mine airway rock surfaces. The introduction of TSL material in mine airways could therefore serve to reduce system friction head losses while maintaining good environmental quality (dust reduction) and improving mechanical support performance.

A field determination of friction factor parameters was conducted by de Souza and Archibald (2002) in conjunction with a field application. As shown in Figure 10, the field application was carried in a $91 \mathrm{~m}$ long, stable fresh air drift at an underground mine. The airway resistance, friction factor, and roughness height were calculated from the data from three ventilation surveys. The results indicated that the liner, on average, decreased the airway resistance by $7.44 \%$, the friction factor by $7.42 \%$, and the roughness by $12.19 \%$. However, only one TSL material was tested and the benefits of TSL for ground support were not investigated in this study.

\section{Summary}

This paper reviewed the current gas management challenges and presented the potential benefits of TSLs for gas management in underground coal mines. These may include reducing gas emissions into the ventilation system, enhancing the in-seam drainage performance, and controlling spontaneous combustion.

Since their introduction, TSLs have received increasing attention from the mining industry around the world due to the significant benefits they bring, such as low volume, rapid application, and rapid curing, with great potential to reduce mining costs. However, this technology is not yet mature and is still under development. Most of the products on the markets are still undergoing study and field trials.

For safety reasons, reactive TSLs such as polyurethane-, polyurea-, or methacrylate-based materials are not recommended for underground applications. Most of the

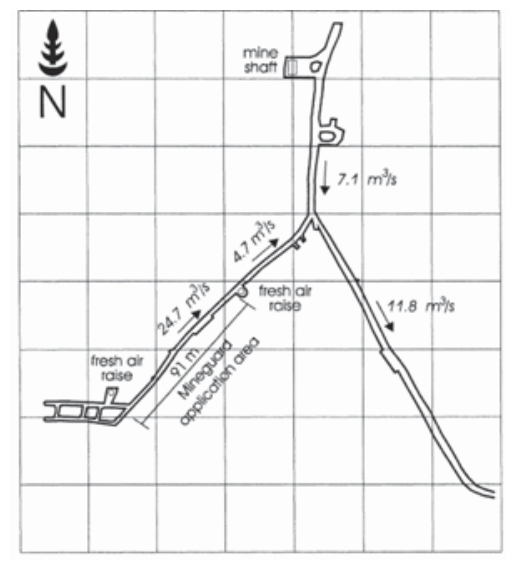

Figure 10-Mine level plan schematic (de Souza and Archibald, 2002) products on the market are nonreactive TSLs with modifications to reduce the curing time.

Motivated by the potential for using TSLs as a barrier against gas movement, many tests have been conducted to investigate the permeability characteristics of different TSLs, either with or without considering the interaction with the substrate. Among all the TSL materials tested, the polymer/cementitious-based TSLs have the lowest permeability and are recommended for gas management in underground coal mines from a permeability perspective.

Gas emissions can adversely affect safety and production in underground coal mining. Appropriate approaches and equipment are needed for controlling gas emissions in order to provide safe working conditions. Ventilation and gas drainage are the most important techniques for this purpose. However, irregular gas emissions will usually increase the gas concentration in the roadways and slow down or even stop development. To address this issue, TSLs have the potential to be used as a 'cosmetic' support for sealing the fractured zone and decreasing the irregular gas emissions.

During underground in-seam drainage, the application of a TSL may prevent gas migration into the drainage holes through the fractures near the ribs, thus increasing the drained gas purity and gas production. Furthermore, the application of TSL can also help decrease the rib emissions to the ventilation environment.

TSLs have the potential for controlling spontaneous combustion by sealing the leakage path and thereby reducing the oxygen level in the spontaneous combustion locality. In fact, if applied early enough, TSLs could also prevent the occurrence of spontaneous combustion.

The application of TSLs could also potentially reduce the friction resistance of the ventilation airway, thereby reducing power and ventilation costs.

\section{Recommendations}

TSLs show potential to be used as a gas management tool in underground coal mines. However, there has been limited research into this topic. It is obvious that further investigation is needed in order to ascertain whether this technology can have a significant impact on gas management. Multiple laboratory and field tests under various conditions are recommended. The application procedures for TSLs in gas management in underground coal mines should also be studied and incorporated with the laboratory and field test results. Furthermore, an optimized application procedure of TSLs for gas management should be put forward.

Besides gas management, the application of TSLs can also bring many other benefits, such as in ground support and ventilation. A financial and technical model should be built to evaluate the cost-benefit of using TSLs in the coal mining industry.

\section{References}

ARchiBALD, J.F. 2001. Assessing acceptance criteria for and capabilities of line for mitigating ground falls. Proceedings of the Mining Health and Safety Conference, Sudbury, Ontario, Canada. pp. 1-31.

ARchibaLd, J.F. 2004. Canadian laboratory and field testing. Surface Support in Mining. Potvin, Y., Stacey, D. and Hadjigeorgiou, J. (eds.). Australian Centre for Geomechanics, Perth, Western Australia. pp. 73-88. 


\section{Potential use of thin spray-on liners for gas management}

Archibald, J.F. and De SouzA, E. 1993. Mine support, radiation and ventilation control with spray-on barriers. Proceedings of the American Nuclear Society Symposium on High Level Nuclear Waste Management, Las Vegas, NV. pp. $1770-1777$.

BELFIELD, S. 2006. Spray-on liners need goal posts. Australian Mining, vol. 98 no. 10. p. 40.

BLACK, D. and AzIZ, N. 2008. Improving UIS gas drainage in underground coal mines. Proceedings of the 2008 Coal Operators' Conference, University of Wollongong, NSW, Australia. Aziz, N. (ed.). pp. 186-196.

BLAcK, D.J. and AzIz, N. 2009. Reducing coal mine GHG emissions through effective gas drainage and utilisation. Proceedings of the 2009 Coal Operators' Conference, University of Wollongong, NSW, Australia. pp. 217-224.

BRUNNER, D., SchWoEBeL, J., and LI, J. 1997. Simulation based degasification system design for the Shihao Mine of the Songzao coal mining administration in Sichuan China. Proceedings of the Sixth International Mine Ventilation Congress, Pittsburgh, PA. Ramani, R.V. (ed.). Society for Mining, Metallurgy and Exploration, Littleton, CO.

CARStens, R. and Oosthuizen, A.O. 2004. Application of a thin sprayed liner (TSL) in VCR gullies behind advancing stope panels at Savuka Gold Mine. ProceedingS of SANIRE 2004 - The Miner's Guide through the Earth's Crust. South African National Institute of Rock Engineering. pp. 89-94.

CLIFF, D. 2009. Spontaneous combustion management - linking experiment with reality. Proceedings of the 2009 Coal Operators' Conference, University of Wollongong, NSW, Australia. pp. 281-286.

DARLING, P. 2011. SME Mining Engineering Handbook. Society for Mining, Metallurgy and Exploration, Littleton, CO.

De SouZA, E. and Archibald, J.F. 2002. Reduction in airflow resistance charac teristics with thin spray-on liners. Proceedings of Mine Ventilation: the North American/Ninth US Mine Ventilation Symposium, Kingston, Ontario, Canada. CRC Press. pp. 51-56.

DiRIGE, A. and ARChiBALD, J. 2009. Numerical modeling simulations of spray-on liners support potential in highly stressed and rockburst prone rock conditions. Proceedings of the 3rd Canada-US Rock Mechanics Symposium, Toronto, Ontario, Canada. Diederichs, M. and Grasselli, G. (eds). Canadian Rock Mechanics Association. pp. 1-9.

Dubois, G., Kravits, S., ReILly, J., and Mucho, T. 2006. Target drilling's long boreholes maximize longwall dimensions. Proceedings of the 11th US/North American Mine Ventilation Symposium, PA, USA. CRC Press. pp. 463-468.

EFNARC. 2008. Specification and guidelines on thin spray-on liners for mining and tunnelling.

ESPLEY-BOUdREAU, S.J. 1999. Thin spray-on liner support and implementation in the hardrock mining industry. Master's thesis, Laurentian University, Sudbury, Ontario, Canada.

Fowkes, N., Teixeira De Freitas, J.A., and Stacey, R. 2008. Crack repair using an elastic filler. Journal of the Mechanics and Physics of Solids, vol. 56, no. 9. pp. 2749-2758.

GERARD, C. 2007. Application for thin spray-on liners in Australian underground coal mines. Bachelor's thesis, University of New South Wales, Sydney, Australia.

Gillies, S. and Wu, H.W. 2013. Australian longwall panel ventilation practices Proceedings of the 2013 Coal Operators' Conference, University of Wollongong, NSW, Australia. pp. 176-183.

GolsBy, A. 2015. New generation polymer technology available to be used in plaster and cementitious fibre and non-fibre spray on and grout system. Proceedings of the 2015 Coal Operators' Conference, University of Wollongong, NSW, Australia. .Aziz, N. and Kininmonth, B. (eds.) pp. 183-191

Ham, B. 2005. A review of spontaneous combustion incidents. Proceedings of Coal2005: 6th Australasian Coal Operators' Conference, Brisbane, Queensland, Australia. pp. 237-242.
Hussain, F., Saydam, S., Mitra, R., and Cinar, Y. 2012. Experimental study for reducing gas inflow by use of thin spray-on liners in underground coal mines. Mining Technology, vol. 121, no. 2. pp. 61-67.

Jjuuko, S. and Kalumba, D. 2014. A review of application and benefits of thin spray-on liners for underground rock support in South African mines. Proceedings of the 8th South African Young Geotechnical Engineers Conference, Spier Conference Centre, Stellenbosch, Western Cape. p. 10.

KAISER, P.K. and SuorinEnI, F. 2006. Guidelines for applications of Masterseal $845 \mathrm{~A}$.

KARACAN, C.Ö. 2008. Modeling and prediction of ventilation methane emissions of US longwall mines using supervised artificial neural networks. International Journal of Coal Geology, vol. 73, no. 3-4. pp. 371-387.

Karacan, C.Ö., Diamond, W.P., and Schatzel, S.J. 2007. Numerical analysis of the influence of in-seam horizontal methane drainage boreholes on longwall face emission rates. International Journal of Coal Geology, vol. 72, no. 1. pp. 15-32.

Karacan, C.Ö., Ruiz, F.A., CotÈ, M., and PhiPPS, S. 2011. Coal mine methane: a review of capture and utilization practices with benefits to mining safety and to greenhouse gas reduction. International Journal of Coal Geology, vol. 86, no. 2. pp. 121-156.

KUIJPERS, J.S. 2004. Evaluation of thin spray-on liners support behaviour. Proceedings of Surface Support in Mining, Perth, WA, Australia. Potvin, Y., Stacey, D., and Hadjigeorgiou, J. (eds). Australian Centre for Geomechanics. pp. 103-112.

KujJpers, J.S., Sellers, E.J., Toper, A.Z., Rangasamy, T., Ward, T., Rensburg, A.J., YILMAZ, H., and StAcEY, D. 2004. Required technical specifications and standard testing methodology for thin sprayed linings. Safety in Mines Research Advisory Committee, Johannesburg, South Africa.

LACERDA, L. AND RISPIN, M. 2002. Current ground support membrane applications in North American underground mines. Proceedings of the 2nd International Seminar on Surface Support Liners: Thin Sprayed Liners, Shotcrete and Mesh, Sandton, South Africa. South African Institute of Mining and Metallurgy, Johannesburg.

LAU, V., SAYDAM, S., CAI, Y., and MitRA, R. 2008. Laboratory investigation of support mechanism for thin spray-on liners. Proceedings of the 12th International Conference of the International Association for Computer Methods and Advances in Geomechanics (IACMAG), Goa, India. Curran Associates, Red Hook, NY. pp. 1381-1388.

Lu, S., Cheng, Y., MA, J., and Zhang, Y. 2014. Application of in-seam directiona drilling technology for gas drainage with benefits to gas outburst control and greenhouse gas reductions in Daning coal mine, China. Natural Hazards, vol. 73, no. 3. pp. 1419-1437.

LUNARZEWSKI, L.L.W. 1998. Gas emission prediction and recovery in underground coal mines. International Journal of Coal Geology, vol. 35 no. 1. pp. 117-145.

MASON, D.P. and ABELMAN, H. 2009. Support provided to rock excavations by a system of two liners. International Journal of Rock Mechanics and Mining Sciences, vol. 46, no. 7. pp. 1197-1205.

MASON, D.P. and STACEY, T.R. 2008. Support to rock excavations provided by sprayed liners. International Journal of Rock Mechanics and Mining Sciences, vol. 45, no. 5. pp. 773-788.

MASS, J.J. and RENKEn, K.J. 1997. Laboratory assessment of cementitious coatings as a barrier to radon gas entry. Proceedings of the 1997 International Radon Symposium, Cincinnati, $\mathrm{OH}$, American Association of Radon Scientitts and Technologists, Fletcher, NC. pp. 1.1-1.13.

MCPHERSON, M.J. 1993. Subsurface Ventilation and Environmental Engineering. Chapman and Hall, New York.

MoReBY, R. 2005. Management of seam gas emission and spontaneous combustion in a highly gassy, thick and multi seam coal mine - a learning experience. Proceedings of the sth International Mine Ventilation Congress, Brisbane, Australia. Gillies, A.D.S. (ed.). Australasian Institute of Mining and Metallurgy, Melbourne. pp. 221-230. 


\section{Potential use of thin spray-on liners for gas management}

Nagel, M. and Joughin, W.C. 2002. Thin sprayed liner trials at South Deep Mine. Proceedings of the 2nd International Seminar on Surface Support Liners: Thin Sprayed Liners, Shotcrete and Mesh, Sandton, South Africa. South African Institute of Mining and Metallurgy, Johannesburg.

NoAcK, K. 1998. Control of gas emissions in underground coal mines. International Journal of Coal Geology, vol. 35, no. 1-4. pp. 57-82.

NoRTHCROFT, I.W. 2006. Innovative materials and methods for ground support, consolidation and water sealing for the mining industry. Journal of the South African Institute of Mining and Metallurgy, vol. 106, no. 12. pp. 835-844.

OztuRк, H. 2012. Fracture mechanics interpretation of thin spray-on liner adhesion tests. International Journal of Adhesion and Adhesives, vol. 34. pp. 17-23.

PACKHAM, R., Cinar, Y., and Moreby, R. 2011. Simulation of an enhanced gas recovery field trial for coal mine gas management. International Journal of Coal Geology, vol. 85, no. 3-4. pp. 247-256.

PALCHI, V. 2002. Use of Gaussian distribution for estimation of gob gas drainage well productivity. Mathematical Geology, vol. 34, no. 6. pp. 743-765.

PAPPAS, D.M., BARTON, T.M., and ERIC, S.W. 2003. The long-term performance of surface support liners for ground control in a underground limestone mine. Proceedings of the 2nd International Seminar on Surface Support Liners: Thin Sprayed Liners, Shotcrete and Mesh, Sandton, South Africa. South African Institute of Mining and Metallurgy, Johannesburg.

Potvin, Y., Stacey, D., Hadjigeorgiou, J., and Yilmaz, H. 2004. Thin spray-on liners (TSLS) - a quick reference guide. Surface Support in Mining. Potvin, Y., Stacey, D., and Hadjigeorgiou, J. (eds.). Australian Centre for Geomechanics, Perth, WA. pp. 3-43.

PuRI, R. and YEE, D. 1990. Enhanced coal bed methane recovery. Proceedings of the SPE 65th Annual Technical Conference and Exhibition, New Orleans, LA. Society of Petroleum Engineers, Richardson, TX.

Richardson, J., Mitra, R., and SAYDAm, S. 2009. Investigation of thin spray-on liners using numerical modelling. Proceedings of the 43rd US Rock Mechanics Symposium and 4th US-Canada Rock Mechanics Symposium, Asheville, NC. American Rock Mechanics Association, Alexandria, VA.

RISPIN, M. and GARSHOL, K.F. 2003. 'Reactive' vs 'non-reactive' TSLs: a comparison illustrated with two prototype technologies. Proceedings of the 3rd International Seminar on Surface Support Liners: Thin Spray-On Liners, Shotcrete and Mesh, Quebec City, Canada.

SAghafi, A. and RoBERTS, D. 2001. Study of the gas permeability of Tekflex used as a sealant in underground coal mines. CSIRO Energy Technology Group.

Saghafi, A., William, D.J., and LAma, R.D. 1998. Worldwide methane emissions from underground coal mining. Proceedings of the 6th International Mine Ventilation Congress, Pittsburgh, PA. Ramani, R.V. (ed.). Society for Mining, Metallurgy, and Exploration, Littleton, CO. pp. 17-22.

SAYDAM, S. and DoCRAT, Y.S. 2007. Evaluating the adhesion strength of different sealants on kimberlite. Proceedings of the 11th Congress of the International Society of Rock Mechanics, Lisbon, Portugal. Taylor and Francis. pp. 585-588.

Schatzel, S.J., Karacan, C., Krog, R., Esterhuizen, G., and Goodman, G. 2008. Guidelines for the prediction and control of methane emissions on longwalls. Department of Health and Human Services, Centers for Disease Control and Prevention, National Institute for Occupational Safety and Health, Pittsburgh Research Laboratory.

Simion, S., Tотн, I., and CiocleA, D. 2005. New technologies used for the prevention of spontaneous combustion occurences in coal mines. Proceedings of the Eighth International Mine Ventilation Congress, Brisbane, Queensland. Gillies, A.D.S. (ed.). Australasian Institute of Mining and Metallurgy, Melbourne. pp. 507-510.

Spearing, A.J.S., BorejSzo, G., and CAmpoli, A. 2009. The application of a structural thin support liner (TSL) on mines. Proceedings of the 43rd US
Rock Mechanics Symposium and 4th US-Canada Rock Mechanics Symposium, Asheville, NC. American Rock Mechanics Association, Alexandria, VA.

StACEY, T.R. 2001. Review of membrane support mechanisms, loading mechanisms, desired membrane performance, and appropriate test methods. Journal of the South African Institute of Mining and Metallurgy, vol. 101, no. 7. pp. 343-351.

State Administration Of Coal Mine Safety. 2014. Government web site accident query system. http://media.chinasafety.gov.cn:8090/iSystem/ shigumain.jsp [Accessed 7 May, 2014]

TANNANT, D.D. 2001. Thin spray-on liners for underground rock support testing and design issues. Proceedings of the 1st International Seminar on Surface Support Liners: Membrane, Shotcrete and Mesh, Perth, WA.

TAnNAnT, D.D. and WAng, C. 2002. Thin rock support liners modeled with particle flow code. Proceedings of the Third International Conference on Discrete Element Methods, Santa Fe, NM, 23-25 September 2002. Cook, B.K. and Jensen, R.P. (eds.). American Society of Civil Engineers, Reston, VA. pp. 346-354

Tenney, J., Chalmers, D., and LI, Z. 2015. Thin spray-on liners potential in reducing dilution of in situ gas in coal mines. Proceedings of the Australian Mine Ventilation Conference 2015, University of New South Wales, Australia.. Belle, B. (ed.). BPA Digital, Australia. pp. 323-328.

THAKUR, P.C. 2006. Coal seam degasification. Handbook for Methane Control in Mining. Kissell, F.N. (ed.). National Institute for Occupational Safety and Health, Pittburgh, PA.

Thyrock, K., Gollnick, I., WyinK, U., And Thiele, G. 2010. Application of thin spray-on liner (Masterseal) at longwall T-Junction sections in German hard coal mines. Proceedings of the 29th International Conference on Ground Control in Mining, Morgantown, WV.

United NATions. 2010. Best practice guidance for effective methane drainage and use in coal mines. 9211170184. Economic Commission for Europe, and Methane to Markets Partnership.

VUTUKURI, V. and LAMA, R. 1986. Environmental Engineering in Mines, Cambridge University Press.

WANG, C. and TANNANT, D.D. 2004. Rock fracture around a highly stressed tunnel and the impact of a thin tunnel liner for ground control. International Journal of Rock Mechanics and Ming Sciences, vol. 41, no. 3. pp. 676-683.

XIA, T., ZHou, F., Liu, J., and GAO, F. 2014a. Evaluation of the pre-drained coal seam gas quality. Fuel, vol. 130. pp. 296-305.

Xia, T., Zhou, F., Liu, J., Kang, J., and Gao, F. 2014b. A fully coupled hydrothermo-mechanical model for the spontaneous combustion of underground coal seams. Fuel, vol. 125, June 2014. pp. 106-115.

YILMAZ, H. 2007. Shear-bond strength testing of thin spray-on liners. Journal of the Southen African Institute of Mining and Metallurgy, vol. 107. pp. 519-530.

YILMAZ, H. 2011. Development of testing methods for comparative assessment of thin spray-on liner (TSL) shear and tensile properties. PhD thesis, University of the Witwatersrand, Johannesburg.

Yilmaz, H., SAydAm, S., and ToPer, A.Z. 2003. Emerging support concept: thin spray-on liners. Proceedings of the 18th International Mining Congress and Exhibition of Turkey, Antalya, Turkey. Chamber of Mining Engineers of Turkey.

ZHou, F., Hussain, F., and Cinar, Y. 2013a. Injecting pure $\mathrm{N}_{2}$ and $\mathrm{CO}_{2}$ to coal for enhanced coalbed methane: experimental observations and numerical simulation. International Journal of Coal Geology, vol. 116. pp. 53-62.

Zhou, F., Hussain, F., Guo, Z., Yanici, S., and Cinar, Y. 2013b. Adsorption/desorption characteristics for methane, nitrogen and carbon dioxide of coal samples from Southeast Qinshui Basin, China. Energy, Exploration \& Exploitation, vol. 31, no. 4. pp. 645-666.

Zhou, S. and Lin, B. 1998. The Theory of Gas Flow and Storage in Coal Seams. China Coal Industry Publishing House, Beijing. 